\title{
Challenges in developing mucosal vaccines and antibodies against infectious diarrhea in children
}

\section{Daisuke Tokuhara}

\begin{tabular}{|c|l|}
\hline Citation & Pediatrics International, 60(3); 214-223 \\
\hline Issue Date & $2018-03$ \\
\hline Type & Journal Article \\
\hline Textversion & Author \\
\hline \multirow{3}{*}{ Rights } & $\begin{array}{l}\text { This is the peer reviewed version of the following article: Pediatrics International, } \\
\text { Volume 60, Issue 3, p.214-223., which has been published in final form at } \\
\text { https://doi.org/10.1111/ped.13497. This article may be used for non-commercial } \\
\text { purposes in accordance with Wiley Terms and Conditions for Self-Archiving. }\end{array}$ \\
\hline DOI & \begin{tabular}{l}
$10.1111 /$ ped.13497 \\
\hline
\end{tabular} \\
\hline
\end{tabular}

\author{
Self-Archiving by Author(s) \\ Placed on: Osaka City University
}

TOKUHARA D. (2018). Challenges in developing mucosal vaccines and antibodies against infectious diarrhea in children. Pediatrics International : Official Journal of the Japan Pediatric Society. 60, 214-223. https://doi.org/10.1111/ped.13497. 
Category of manuscript; Review article

Title; Challenges in developing mucosal vaccine and antibodies against infectious diarrhea in children

Running title; Mucosal vaccine and oral antibody drug

Daisuke Tokuhara, M.D., Ph.D.

Department of Pediatrics, Osaka City University Graduate School of Medicine, Japan

Correspondence to;

Daisuke Tokuhara, M.D., Ph.D.

Assistant professor,

Department of Pediatrics, Osaka City University Graduate School of Medicine

1-4-3, Asahimachi, Abenoku, Osaka, 545-8585, Japan

E-mail: m1155519@med.osaka-cu.ac.jp

TEL: +81-6-6645-3816, FAX; +81-6-6636-8737 


\begin{abstract}
Infectious diarrhea in children can be life-threatening and imposes a large economic burden on healthcare systems, therefore more effective prophylactic and therapeutic drugs are needed urgently. Because most of the pathogens responsible for childhood diarrhea infect the gastrointestinal mucosa, providing protective immunity at the mucosal surface is an ideal way to control pathogen invasion and toxic activity. Mucosal (e.g., oral, nasal) vaccines are superior to systemic (subcutaneous or intramuscular) vaccination for conferring both mucosal and systemic pathogen-specific immune responses, and for the past 50 years, great efforts has been focused on the development of cost-effective mucosal vaccines. Recent progress in plant genetic engineering has revolutonized the production of inexpensive and safe recombinant vaccine antigens. For example, rice plant biotechnology has facilitated the development of a cold-chain-free rice-based oral subunit vaccine against Vibrio cholerae. Furthermore, this technology has led to the creation of a rice-based oral antibody for prophyalaxis and treatment of rotavirus gastroenteritis. This review summarizes current perspectives regarding the mucosal immune system and the development of mucosal vaccines and therapeutic antibodies, particularly rice-based products, and discusses future prospects regarding mucosal vaccines for children.
\end{abstract}

Key Words; Mucosal Immunity, Rice-based vaccine, Vibrio cholerae, rotavirus, antibody fragments 


\section{Introduction}

Despite the general improvement in children's health worldwide, infectious diarrhea remains a major cause of death after pneumoniae in children younger than 5 years $(>1$ month), thus accounting for 0.61 million deaths annually, which is approximately $16 \%$ of total deaths (3.2 million) in that population. ${ }^{1}$ Childhood deaths attributable to diarrhea are predominant in developing countries, ${ }^{1}$ whereas in developed countries, infectious diarrhea has low mortality but causes a huge financial burden on healthcare systems due to physician visits and hospitalizations. ${ }^{2-4}$ In the United States, norovirus infection causes more than $\$ 273$ million in treatment costs annually for hospitalizations $(>14,000)$, emergency department visits (> 281,000), and outpatient visits (> 627,000) among children younger than 5 years. $^{2}$ Therefore controlling infectious diarrhea for children is a great mission and challenge in both developed and developing countries. Because most of the pathogens responsible for childhood diarrhea deaths and hospitalizations, such as norovirus, rotavirus, Vibrio cholerae, enterotoxigenic Escherichia coli, and nontyphoidal Salmonella spp. infect the mucosal surface at the gastrointestinal tract, ${ }^{5}$ bolstering the active or passive host defense against pathogens at the digestive mucosal surface is a rational strategy.

In order to provide the pathogen-specific active host defense, vaccines that effectively induce both mucosal and systemic acquired immunity are idealy required for the control of gastrointestinal infectious diseases. In this regard, there are two major options for vaccine administration; systemic vaccination by using intramuscular or subcutaneous injection and 
mucosal vaccination by using oral or nasal administration. Injection-type vaccines induce a strong pathogen- or toxin-specific IgG antibody at the systemic compartment, whereas they are less effective in eliciting pathogen-specific protective immunity at the mucosal compartment. ${ }^{6}$ In contract, the delivery of vaccines across mucosal surfaces, such as by the oral or nasal route, effectively stimulates the mucosal immune system and provides pathogen-specific mucosal immune responses in addition to systemic immune responses as described in this review. ${ }^{6}$ Therefore, like the currently approved oral vaccines against rotavirus and Vibrio cholerae ${ }^{7-9}$ most of current vaccine candidates against diarrheal pathogens were developed as mucosal (typically oral) vaccines to deliver antigen to mucosal inductive sites, such as Peyer's patches (PPs), or to stimulate mucosal antigen-presenting cells (APCs) such as dendritic cells (DCs). ${ }^{10,11}$

Alternative approach against infectious diarrhea is to provide passive immunity at the mucosal surface by using pathogen-specific antibody. The clinical use of oral antibody drug is restricted to geographic regions for which approved vaccines are unavailable or showed low efficacy, during outbreaks, and in immunosuppresed patients. ${ }^{12-15}$ However since the 1980s, advances in antibody engineering and the discovery of camel heavy-chain antibodies (VHHs), which constitutes the smallest antigen-binding domain associated with high binding capacity and pepsin-, acid-, and heat-stable features ${ }^{16,17}$ have accelerated the development of oral antibody fragments and thus interest in the concept of oral antibody prophylaxis and therapy. No oral antibody drugs are approved for human use currently, but anti-rotavirus 
VHHs are to become antibody drug candidates in light of accumulated evidence regarding their efficacy in reducing diarrhea in mouse pups and in infants. ${ }^{18,19,20}$

In addition to effectiveness, important aspects in getting mucosal vaccine and oral antibody drug to market are safety and low production cost. In this regard, plant-based protein production system can yield high quantities of recombinant proteins that are not contaminated with pathogens of animals or humans; these features enhance product safety and reduce production costs compared with those associated with conventional recombinant

protein techniques using mammalian cells, bacteria, yeast, or baculovirus. ${ }^{21}$ No plant-based products are liscensed for human use currently, but rice-based recombinant protein technology, established in Japan, has been used to develop cold-chain-free oral vaccine and antibody drug candidates, ${ }^{6,22-27}$ and a rice-based oral cholera vaccine is preparing for phase II clinical trial aimed toward garnering approval for human use.

This review summarize current perspectives of mucosal immune system as it relates to the development of mucosal vaccines and antibody drug, focusing on rice plant-based products that are already or expected to soon be under clinical trial, and discuss for the future outlook regarding mucosal vaccine development for children.

\section{The mucosal immune system}

Gastrointestinal surfaces are protected against pathogen invasion both specifically and non-specifically through physical, chemical and immunologic defense mechanisms (Fig. 1a). 
One component of the nonspecific defense system that protects against pathogen invasion is the physical barrier, which comprises epithelial cells covered with mucus. ${ }^{28}$ Antimicrobial proteins, such as defensins and lysozymes, typically are produced by epithelial cells and kill or inactive microorganisms by attacking the basic cell wall structures of bacteria. ${ }^{29}$ Lactoferrin, a protein generally derived from breast milk, inhibits bacterial growth through iron-dependent and -independent mechanisms. ${ }^{30}$ Pathogen-specific defense schemes rely on both cellular and humoral immunity. In terms of cellular immunity, mucosal cytotoxic $\mathrm{T}$ lymphocytes (CTLs) are crucial for the immune clearance of pathogenesis. Pathogen-specific CTLs typically are induced after the mucosal administration of live or attenuated pathogens or by using oral vaccine antigens with strong adjuvants such as cholera toxin (CT) or heat-labile enterotoxin (LT). Regarding humoral immunity, secretory IgA (SIgA) plays a key role in gut protection. The IgA found in serum typically is monomeric, whereas mucosally secreted $\operatorname{IgA}$ is dimeric or polymeric and is associated with the secretory component, which provides enzymatic resistance, thus effectively inhibiting pathogen invasion and toxin activity in the protease-containing gut lumen. ${ }^{31}$ Gut-associated lymphoid tissue (GALT), which is predominantly composed of PPs, isolated lymph nodules, and mesenteric lymph nodes, is critical for effectively inducing the production of antigen specific-SIgA.

Beneath the follicle-associated epithelium (FAE) of PPs, antigen-presenting cells (APCs) such as DCs, B cells, and T cells construct the immune networks that lead to the induction of 
acquired immunity and oral tolerance (Fig. 1a). In the FAE, pathogens or orally administered antigens are taken up by M cells, which form intraepithelial pockets specialized for the transepithelial transport of antigen. ${ }^{32}$ Alternatively, antigens are taken up by intestinal villous M cells (Fig. 1a,b) ${ }^{33}$ In PPs, APCs beneath the M cells capture antigens, which are processed and then presented to $\mathrm{CD} 4^{+}$and $\mathrm{CD} 8^{+} \alpha \beta \mathrm{T}$ cells. Activated T cells secrete the cytokines such as transforming growth factor (TGF- $\beta$ ) and IL-4 to promote class-switching of B cells to produce IgA (Fig.1b). The cytokines secreted from mucosal T cells (IL-4 and TGF- $\beta$ ) and epithelial cells (TGF- $\beta$ ) cooperate to promote the maturation of IgA-producing B cells. Furthermore, intestinal DC-derived retinol, a metabolite of vitamin A, enhances the expression of $\alpha 4 \beta 7$ integrin and CC chemokine receptor 9 (CCR9) on T and B cells upon activation and imprints them with 'gut-homing' specificity. ${ }^{34,35}$ Through gut-homing, the activated $\mathrm{T}$ and $\mathrm{B}$ cells migrate from PPs through the efferent lymphatics to the regional mesenteric lymph nodes and then to the intestinal lamina propria by way of lymphatic ducts and blood circulation. ${ }^{36}$

As just mentioned, the trafficking of activated $\mathrm{B}$ and $\mathrm{T}$ cells from the blood to the intestinal lamina propria (that is, gut-homing) is regulated by interactions involving $\alpha 4 \beta 7$ integrin and CCR9 (Fig. 1b). Small intestinal microvascular endothelial cells express mucosal vascular addressin cell adhesion molecule 1 (MAdCAM-1), which binds to $\alpha 4 \beta 7$ integrin. In addition, endothelial cells release CC chemokine ligand 25 (CCL25), which bind to CCR9, its receptor for CCL25; therefore, activated B and T cells expressing $\alpha 4 \beta 7$ integrin 
and CCR9 are attracted to the lamina propria. ${ }^{37,38}$ In addition, epithelial cells also produce CCL25, further attracting immune cells to the lamina propria below the villous epithelium. In the presence of various cytokines, including IL-5 and IL-6, IgA-committed B cells differentiate into IgA-producing plasma cells. Dimeric or polymeric IgA released from the plasma cells attaches to the polymeric immunoglobulin receptor (pIgR) located on the basolateral surface of mucosal epithelial cells, is transcytosed to the apical surface, and is then secreted into the mucus layer (Fig. 1c). ${ }^{31}$ During transcytosis, a portion of pIgR is cleaved off; the remaining portion stays attached to $\operatorname{IgA}$ and is therefore called the secretory component. Therefore, $\operatorname{IgA}$, rather than $\operatorname{IgG}$ or $\operatorname{IgM}$, is the predominant immunoglobulin isotype in most mucosal secretions. SIgA attaches to the pathogenic microorganisms and toxin and block their access to the mucosal epithelial cells. Furthermore, M cell-mediated reverse transcytosis of antigen-SIgA complex contributes to the presentation and processing by the APCs, leading to an adaptive immune response against the antigen.

\section{Mucosal Vaccines}

According to our understanding of the mucosal immune system, vaccine antigens must be administered to mucosal inductive sites such as PPs to induce mucosal-specific protective immunity. Consequently, systemic (intramuscular or subcutaneous) vaccination, which does not deliver antigen to mucosal inductive sites, is minimally effective in stimulating the mucosal immune system. In addition, the particular gut-homing system used is dependent on 
the mucosal site (that is, gut or nasal) where the antigen is administered. Nasally administered vaccine antigens provide specific mucosal immunity predominantly in the respiratory tract, ${ }^{36,39,40}$ but poorly induce specific SIgA in the gut. Therefore, the oral route is the more appropriate route for vaccination against diarrheal pathogens, compared with the nasal route. On this basis, the currently licensed vaccines against diarrheal diseases - inactivated whole-cell cholera vaccine $\left(\right.$ Shanchol $\left.{ }^{\circledR}\right)$, inactivated whole-cell recombinant B subunit cholera $(\mathrm{CTB})$ vaccine $\left(\right.$ Dukoral $\left.^{\circledR}\right)$, and live attenuated rotaviral vaccines $\left(\right.$ Rotarix $^{\circledR}$ and RotaTeq $\left.^{\circledR}\right)$ - were developed as oral vaccines and effectively reduce pathogen-induced diarrhea in children. ${ }^{7,8,941}$ However, conventional whole-cell or whole-virus vaccines are costly in terms of the need to maintain a low-temperature supply chain (that is, 'cold chain') and are associated with underlying risks for infectious contaminants or reversion to virulence (in the case of live attenuated vaccines). Therefore, there is a growing demand for improvements of existing vaccines in terms of improved cost-effectiveness, storage and safety.

During the late 1980s and early 1990s, progress in immunology, molecular biology, and recombinant gene technologies contributed to the development of new vaccine candidates based on the subunit principle, in which a pathogenic component is used as a vaccine antigen (e.g., the cholerae toxin B subunit, toxin-coregulated pili of Vibrio cholerae, Helicobacter pylori urease, VP4 and VP7 rotavirus capsid protein antigens). ${ }^{42-46}$ However, these recombinant vaccine antigens have several drawbacks. First, these antigens are easily 
digested by gastric acid, which hampers their delivery to mucosal inductive sites (that is, PPs). Second, these recombinant antigens are less immunogenic than are whole-cell vaccines. Third, conventional recombinant protein production methods using bacteria, yeast, or mammalian cells are costly in terms of production and purification; furthermore, the products are associated with a risk of infectious contaminants. To resolve these problems, the development of mucosal vaccines focused on 1) drug-delivery systems, which protected vaccine antigens from degradation by gastric acids or delivered the antigen directly to the immune-inductive tissue (such as PPs) or M cells, 2) adjuvants, to stimulate the acquired immune system by activating immune cells (mainly DCs), and 3) production systems that produced vaccine antigen at low cost and without infectious contaminants.

In regard to drug-delivery systems, an M cell-targeting vaccine using anti-M cell specific antibody, ${ }^{47}$ a microcapsule vaccine promoting effective antigen uptake by $\mathrm{M}$ cells, ${ }^{48}$ and a rice-based vaccine that escapes protease-mediated degradation have been developed. ${ }^{22}$ In addition, mucosal adjuvants including enterotoxins, CT, and LT have been shown to induce strong antigen-specific immune responses $;{ }^{10,11,49}$ however, these enterotoxins cannot be used in humans because of their toxicity. Therefore, various alternative mucosal adjuvants, including non-toxic mutant CT or LT, CTB, and toll-like receptor (TLR) agonists that target pattern recognition receptors on DCs, have been studied. ${ }^{10,11,50}$

Another important aspect to resolve regarding mucosal vaccine development is the cost-effective production of vaccine antigen. Since the late 1990s, plant genetic engineering 
has made it possible to produce vaccine antigen protein in plants, including rice, tobacco, maize, potato, lettuce, and carrot. ${ }^{51-57}$ Plants yield high amounts of recombinant proteins that are free of contamination by animal or human pathogens. ${ }^{21}$ Most of the plants used for protein synthesis have been edible plants (e.g., rice, potato, lettuce); thus, plant biotechnology has led to the concept of edible vaccines, which eliminate the costs associated with protein purification. In addition, when administered orally, plant-based antigens can induce both mucosal and systemic immune responses to provide protection against pathogen-induced diarrhea. ${ }^{51-57}$ Because vaccine price, including the costs and methods of vaccine storage, delivery, and administration (e.g., needles, syringes), can limit the ability of a country (especially developing countries) to immunize its population, plant-based pharmaceuticals hold great promise for bringing cost-effective and safe vaccines to market.

\section{Rice-based vaccines}

Rice is an attractive candidate antigen-expressing plant for vaccine production because rice seed is suitable for long-term preservation of antigen protein without the need of a cold chain (i.e., refrigerated storage), and it is resistant to digestion by gastric acids. Prof. Hiroshi Kiyono and Dr. Yoshikazu Yuki (Division of Mucosal Immunology, Institute of Medical Science, University of Tokyo) used the unique biologic characteristics of rice seed to devise a new vaccine production, preservation, and delivery system (Fig. 2). ${ }^{6,22}$ Agrobacterium tumefaciens naturally infects and introduces its T-DNA region into plants. Using this 
characteristic, the T-DNA region of $A$. tumefaciens can be replaced with a vaccine antigen gene, which subsequently is introduced into the rice callus, a mass of undifferentiated rice plant cells. Once a transgenic line that stably produces the target protein is established, it can be used as a permanent source of vaccine antigen and established as a master seed bank. Using the method described, we created a plant-based anti-cholera vaccine by expressing the CTB subunit in rice (Fig. 2). ${ }^{6,22}$ In cholera, V. cholerae-producing CT, which consists of a dimeric A subunit (CTA) and pentameric CTB, causes diarrhea. CTB, the non-toxic component of CT, binds to intestinal epithelial cells by means of the GM1 receptor. ${ }^{58}$ After endocytosed, CTA is released, consequently inhibiting the uptake of sodium chloride by villi and stimulating active chloride secretion by crypt cells; together these effects cause severe diarrhea and fluid loss. ${ }^{58}$ Therefore, using anti-CTB sIgA antibody to inhibit CTB from binding to the GM1 receptor might prevent diarrhea or reduce its severity (Fig. 2).

According to this concept, using an Agrobacterium-mediated method to transduce the gene encoding CTB into rice seed achieved an average of $30 \mu \mathrm{g}$ of recombinant CTB protein per transgenic rice seed, thus characterizing our system as a high-protein antigen production system. ${ }^{22}$ In addition, recombinant CTB accumulated in the rice protein body (PB), which protected the CTB from pepsin digestion, suggesting that the rice PB acts as a natural capsule for oral administration of the vaccine. ${ }^{22}$ Furthermore, oral immunization of mice with rice-based CTB elicited CTB-specific serum $\operatorname{IgG}$ and intestinal $\operatorname{Ig}$ A antibodies and protected the animals from CT-induced diarrhea (Fig. 2). ${ }^{6,22}$ An experiment in pIgR-deficient 
mice, which lack the production and transepithelial transport of SIgA, revealed that intestinal CTB-specific SIgA, not serum IgA or IgG, was responsible for humoral protective immunity against CT-induced diarrhea. ${ }^{6}$ These results demonstrate that rice-based CTB-induced SIgA played a critical role in providing protection against CT-induced diarrhea. In addition, oral immunization with rice-based CTB that had been stored at room temperature for $>3$ years induced CTB-specific serum IgG and intestinal SIgA responses at the same levels as those induced by freshly harvested rice-based CTB in mice. ${ }^{6}$ This result suggests that a major advantage of this system is that the vaccine can be stored for long periods without the need for a cold chain, which will be a particular advantage in developing countries. As a step toward using rice-based CTB in humans, a previous study has confirmed that vaccination with MucoRice-CTB induces CTB-specific SIgA without adverse effects in non-human primates (that is, Macaca fascicularis). ${ }^{27}$ In addition, because the amino acid sequence and protein conformation of $\mathrm{CT}$ are similar to those of the LT produced by enterotoxigenic Escherichia coli (ETEC), the cause of travelers' diarrhea, rice-based CTB likely will be effective against ETEC-induced diarrhea. Rice-based CTB has also shown effectiveness in protection against ETEC-induced diarrhea in mice and pigs. ${ }^{6,25}$

In 2006, a tobacco-based vaccine against Newcastle disease virus was the first plant-based vaccine approved by the United States of Department of Agriculture for veterinary use. ${ }^{59}$ The effectiveness of the rice-based vaccine against pig ETEC may accelerate the veterinary use of rice-based CTB prior to its use in humans. Only a few plant-based vaccines have reached 
human clinical trials. ${ }^{60-63}$ For example, the safety and immunogenicity of potato- and maize-based oral vaccines expressing LTB against ETEC were confirmed in clinical trials, in which LTB-specific serum $\operatorname{IgG}$ and $\operatorname{IgA}$ were induced in healthy adult volunteers. ${ }^{60}$ In addition, norovirus capsid protein VP1 produced in potato tubers was orally administered to healthy volunteers, and $20 \%$ of vaccinated volunteers developed VP1-specific serum IgG titers. $^{61}$

Following the effectiveness of the rice-based oral cholera vaccine in protecting against diarrhea, a vaccine production system was developed and the produced vaccine was thoroughly characterized in accordance with the governmental regulatory requirements. ${ }^{64-67}$ The rice-based CTB vaccine has been extensively characterized by whole-genome sequencing, proteome analyses, and metabolome analysis. ${ }^{65,67}$ The master seed bank was established, and the rice-based vaccine is produced in a closed cultivation system to minimize variations in antigen expression and quality during vaccine manufacture. ${ }^{64}$ Recent analysis has confirmed that CTB expression in rice seed does not up-regulate known rice allergens. ${ }^{66}$ Fine-powdered rice-based vaccine was evaluated in a physician-initiated phase I study at the Research Hospital of the Institute of Medical Science (University of Tokyo). Further details of this phase I study will be published elsewhere. Due to collaboration with a pharmaceutical company, the rice-based CTB vaccine is preparing for phase II clinical testing aimed at securing approval for use of the vaccine in humans. 


\section{Oral antibody drugs}

As a natural source of passive immunity, IgA antibodies against $V$. cholerae and Campylobacter jejuni in breast milk protected breast-fed children against those pathogen-induced diarrheas. ${ }^{68,69}$ As another way to confer specific passive immunity, oral and intestinal inoculation of monoclonal antibodies against rotavirus capsid protein reduced the severity of rotavirus-induced disease in mice. ${ }^{12,13}$ In humans, the oral administration of bovine milk hyper-immunized by using rotavirus showed effectiveness in reducing rotavirus-induced diarrhea in children. ${ }^{14,15}$ Therefore, the oral administration of antibodies as drugs is an attractive strategy for preventing and treating infectious diarrhea. However, several problems have hampered the practical use of oral antibody drugs: the antibody production and purification processes are costly, and orally administered purified antibody proteins are easily degraded by gastric and intestinal proteases. In 1993, a pepsin-, acid-, heat-stable antibody was discovered: the variable domain of camel heavy-chain antibodies (VHH), which do not possess light chains, constitutes the smallest antigen-binding domain associated with high binding capacity (Fig. 3). ${ }^{16}$ In addition, the expression of VHH antibody fragments in microorganisms was comparable to that of conventional antibody fragments (Fab and $\mathrm{ScFv}) ;{ }^{17}$ consequently VHH antibody technology has rapidly progressed. Oral inoculation of yeast-derived recombinant llama $\mathrm{VHH}$ antibody fragments against rotavirus (ARP1) decreased rotavirus-induced diarrhea in mouse pups. ${ }^{18}$ Lactobacilli producing ARP1 were generated and shown to be effective in the same mouse pup model. ${ }^{19}$ Furthermore, 
orally administered ARP1 produced by yeast safely and effectively reduced the severity of rotavirus-induced diarrhea in children in a phase II clinical trial conducted in Bangladesh. ${ }^{20}$ The anti-rotavirus VHHs are expected to achieve approval for human use.

\section{Rice-based antibody drug}

To produce VHH antibody fragments cost-effectively, plant biotechnology was being applied and demonstrated successfull production of VHHs in rice, tobacco, Arabidopsis thaliana. ${ }^{23,70,71}$ In collaboration with colleagues at the Karolinska Institute, we combined our rice-based biotechnology with VHH technology and successfully developed rice seed that expresses ARP1. ${ }^{23}$ The ARP1 gene, combined with an RNA interference (RNAi) suppression cassette, was transfected into rice plants by using A. tumefaciens-mediated transformation (Fig. 3). ${ }^{23}$ Through RNAi technology, the production of rice storage proteins (prolamin and glutelin) was suppressed in the transgenic rice seed, and ARP1 predominantly expressed (Fig. 3). Uniquely, simply mixing water with powdered transgenic rice seed released the rice-based ARP1 as a soluble form, thus achieving a purification-free production process. Furthermore, this methodology achieved an average of $170 \mu \mathrm{g}$ of soluble ARP1 per seed, representing $11.9 \%$ of the total seed protein. In comparison to previous plant-based antibodies (scFV, IgG, Fab, and $\mathrm{VHH}),{ }^{72-75}$ the rice-based production system achieved an extremely high yield of soluble antibodies. In addition, rice-derived ARP1 neutralized the 
human rotoviral strains Wa G1P [8], ST-3 G4P [6], 69M G8P [10], F45 G9P [8], and Va70 G4P $[8] .^{23}$

The outer-layer proteins of rotavirus, VP7 and VP4, both contain neutralizing epitopes, although these tend to be serotype-specific. ${ }^{76}$ In contrast, the middle-layer protein, VP6, is the most abundant and immunodominant viral protein, contains group- and subgroup-determining epitopes, and is recognized by ARP $1 .^{76}$ Therefore, rice-based ARP1 likely provides a broad neutralizing capacity. Furthermore, orally administered rice-based ARP1 markedly decreased the viral load in immunocompetent as well as immunodeficient mice. ${ }^{23}$ Rice-based ARP1 retained in vitro neutralizing activity after long-term storage (>1 year) and boiling and conferred protection in mice even after heat treatment at $94{ }^{\circ} \mathrm{C}$ for 30 $\min$ (Fig. 3) ${ }^{23}$ High-yield, water-soluble, and purification-free rice-based ARP1 thus forms the basis for orally administered prophylaxis and therapy against rotaviral infection.

In the phase-II clinical trial evaluating yeast-derived ARP1, 6- to 24-month-old children with rotaviral diarrhea received ARP1 at $15-30 \mathrm{mg} / \mathrm{kg}$ daily, ${ }^{18}$ which is equivalent to $88-176$ seeds of rice-based ARP1/kg daily. When the rice-based ARP1 is used for those children in the future, ARP1-containing supernatant of the rice water will be orally administered. Rice-based ARP1 represents an approach to the prevention and treatment of rotavirus-induced diarrhea that can reduce the medical and economic burden of the disease in both developed and developing countries and complement current vaccine-based prophylaxis, in situations where live attenuated vaccines are contraindicated. Furthermore, rice-based 
ARP1 does not up-regulate known rice allergens, thus indicating it as a potentially safe oral antibody for clinical application. ${ }^{77}$

\section{Future perspectives of mucosal vaccine and antibody drug development}

Effective mucosal vaccines and antibody drugs are urgently needed for life-threatening diarrheal pathogens for which licensed vaccines are currently unavailable. In this regard, norovirus is a leading cause of virus-induced childhood diarrhea, but an approved noroviral vaccine is unavailable currently, largely due to the lack of an established system for culturing human norovirus. Current norovirus vaccine candidates therefore have used virus-like particles (VLPs) as a vaccine antigen. Because recombinant VLPs are digested by gastric acid, injectable and nasal vaccines have been manufactured and are reported to induce serum specific IgA, ${ }^{78}$ activate antibody-secreting memory $\mathrm{B}$ cells ${ }^{79}$ and effectively reduce diarrhea in healthy adults, ${ }^{80,81}$ but their efficacy in children is undetermined as yet. Compared with adults, children have less exposure to norovirus gastroenteritis, and thus fewer specific memory B cells; consequently vaccine efficacy must be carefully evaluated in children. Efforts to develop plant-based vaccine expressing VLPs, including a rice-based product, are ongoing, and additional mucosal VLP vaccine research focusing on developing antigen-delivery systems and mucosal adjuvants is underway. ${ }^{82-84}$ Otherwise, a recent successful cultivation of human norovirus in enterocytes in stem-cell-derived human intestinal enteroids may lead to the development of a live-attenuated norovirus vaccine. ${ }^{85}$ 
Alternatively, oral antibody drugs against norovirus are under development and are expected to offer alternatives for the prevention and treatment of noroviral gastroenteritis. ${ }^{86}$

Another future perspective is the development of mucosal adjuvants for children.

Neonates and infants are more susceptible to infection and tend to have more severe infection outcomes than do older children and healthy adults. ${ }^{1,87-89}$ In addition, infants need more vaccinations than do adults. ${ }^{7,90-92}$ These characteristics of susceptibility and poor immune induction may underlie the immature innate immunity in neonates and infants. Previous studies using cord blood, which is known to reflect neonatal immunity, revealed that the TLR-mediated innate immune response is impaired in neonates compared with adults. ${ }^{93-96}$ These findings prompted the concept of mucosal vaccines that use adjuvants specialized for children to stimulate the immature innate immune system of this population. We recently found that Zymosan, a cell-wall extract from Saccharomyces cerevisiae that is composed mainly of $\beta$-glucan, is a TLR2 agonist that induces inflammatory immune responses in the monocytes, DCs, and monocyte-derived DCs of human cord blood that are comparable to those in adult blood; ${ }^{97}$ Zymosan is thus likely to be an effective adjuvant in the induction of protective immunity in small children. In addition, the neonatal immune response is influenced by several maternal factors, ${ }^{98}$ and further studies are attempting to disclose appropriate mucosal adjuvants for children.

In conclusion, the mucosal immune system is a unique network that incorporates GALT, sIgA, gut-homing specificity, and so on, and that is separate from the systemic immune 
system. Based on our understanding of the mucosal immune system and advanced technologies such as plant biotechnology and antibody engineering, cost-effective and safe mucosal vaccines and oral antibody drugs against childhood diarrhea are being developed.

Rice-based vaccines and antibody drugs are cold-chain-free, purification-free, and high-yield; are ready for evaluation in clinical trials; and are expected to be the keys to overcoming childhood diarrhea. 


\section{References}

1. Liu L, Oza S, Hogan D, et al. Global, regional, and national causes of under-5 mortality in 2000-15: an updated systematic analysis with implications for the Sustainable Development Goals. Lancet. 2016;388:3027-35.

2. Payne DC, Vinjé J, Szilagyi PG, et al. Norovirus and medically attended gastroenteritis in U.S. children. N. Engl. J. Med. 2013;368:1121-30.

3. Bartsch SM, Lopman BA, Ozawa S, Hall AJ, Lee BY. Global Economic Burden of Norovirus Gastroenteritis. PLoS. One. 2016;11:e0151219.

4. Scallan E, Mahon BE, Hoekstra RM, Griffin PM. Estimates of illnesses, hospitalizations and deaths caused by major bacterial enteric pathogens in young children in the United States. Pediatr. Infect. Dis. J. 2013;32:217-21.

5. Hodges K, Gill R. Infectious diarrhea: Cellular and molecular mechanisms. Gut. Microbes. 2010;1:4-21.

6. Tokuhara D, Yuki Y, Nochi T, et al. Secretory IgA-mediated protection against V. cholerae and heat-labile enterotoxin-producing enterotoxigenic Escherichia coli by rice-based vaccine. Proc. Natl. Acad. Sci. U S A. 2010;107:8794-9.

7. Hill DR, Ford L, Lalloo DG. Oral cholera vaccines: use in clinical practice. Lancet. Infect. Dis. 2006;6:361-73. 
8. Vesikari T, Matson DO, Dennehy P, et al. Rotavirus Efficacy and Safety Trial (REST) Study Team. Safety and efficacy of a pentavalent human-bovine (WC3) reassortant rotavirus vaccine. N. Engl. J. Med. 2006;354:23-33.

9. Ruiz-Palacios GM, Pérez-Schael I, Velázquez FR, et al. Human Rotavirus Vaccine Study Group. Safety and efficacy of an attenuated vaccine against severe rotavirus gastroenteritis. N. Engl. J. Med. 2006;354:11-22.

10. Boyaka PN. Inducing Mucosal IgA: A Challenge for Vaccine Adjuvants and Delivery Systems. J. Immunol. 2017;199:9-16.

11. Pizza M, Giuliani MM, Fontana MR, et al. Mucosal vaccines: non toxic derivatives of LT and CT as mucosal adjuvants. Vaccine. 2001;19:2534-41.

12. Burns JW, Siadat-Pajouh M, Krishnaney AA, Greenberg HB. Protective effect of rotavirus VP6-specific IgA monoclonal antibodies that lack neutralizing activity. Science. 1996;272:104-7.

13. Matsui SM, Offit PA, Vo PT, et al. Passive protection against rotavirus-induced diarrhea by monoclonal antibodies to the heterotypic neutralization domain of VP7 and the VP8 fragment of VP4. J. Clin. Microbiol. 1989;27:780-2.

14. Hilpert H, Brüssow H, Mietens C, Sidoti J, Lerner L, Werchau H. Use of bovine milk concentrate containing antibody to rotavirus to treat rotavirus gastroenteritis in infants. $J$. Infect. Dis. 1987;156:158-66. 
15. Sarker SA, Casswall TH, Mahalanabis D, et al. Successful treatment of rotavirus diarrhea in children with immunoglobulin from immunized bovine colostrum. Pediatr. Infect. Dis. J. 1998;17: 1149-54.

16. Hamers-Casterman C, Atarhouch T, Muyldermans S, et al. Naturally occurring antibodies devoid of light chains. Nature. 1993;363:446-8.

17. Harmsen MM, De Haard HJ. Properties, production, and applications of camelid single-domain antibody fragments. Appl. Microbiol. Biotechnol. 2007;77:13-22.

18. van der Vaart JM, Pant N, Wolvers D, et al. Reduction in morbidity of rotavirus induced diarrhoea in mice by yeast produced monovalent llama-derived antibody fragments. Vaccine. 2006;24:4130-7.

19. Pant N, Hultberg A, Zhao Y, et al. Lactobacilli expressing variable domain of llama heavy-chain antibody fragments (lactobodies) confer protection against rotavirus-induced diarrhea. J. Infect. Dis. 2006;194:1580-8.

20. Sarker SA, Jäkel M, Sultana S, et al. Anti-rotavirus protein reduces stool output in infants with diarrhea: a randomized placebo-controlled trial. Gastroenterology. 2013;14:740-8.

21. Sabalza M, Christou P, Capell T. Recombinant plant-derived pharmaceutical proteins: current technical and economic bottlenecks. Biotechnol. Lett. 2014;36:2367-79. 
22. Nochi T, Takagi H, Yuki Y, et al. Rice-based mucosal vaccine as a global strategy for cold-chain- and needle-free vaccination. Proc. Natl. Acad. Sci. U S A. 2007;104:10986-91.

23. Tokuhara D, Álvarez B, Mejima M, et al. Rice-based oral antibody fragment prophylaxis and therapy against rotavirus infection. J. Clin. Invest. 2013;123:3829-38.

24. Yuki Y, Tokuhara D, Nochi T, et al. Oral MucoRice expressing double-mutant cholera toxin A and B subunits induces toxin-specific neutralising immunity. Vaccine. 2009;27:5982-8.

25. Takeyama N, Yuki Y, Tokuhara D, et al. Oral rice-based vaccine induces passive and active immunity against enterotoxigenic E. coli-mediated diarrhea in pigs. Vaccine. 2015;33:5204-11.

26. Yuki Y, Mejima M, Kurokawa S, et al. Induction of toxin-specific neutralizing immunity by molecularly uniform rice-based oral cholera toxin B subunit vaccine without plant-associated sugar modification. Plant. Biotechnol. J. 2013;11:799-808.

27. Nochi T, Yuki Y, Katakai Y, et al. A rice-based oral cholera vaccine induces macaque-specific systemic neutralizing antibodies but does not influence pre-existing intestinal immunity. J. Immunol. 2009;183:6538-44.

28. McGuckin MA, Lindén SK, Sutton P, Florin TH. Mucin dynamics and enteric pathogens. Nat. Rev. Microbiol. 2011;9:265-78. 
29. Mukherjee S, Hooper LV. Antimicrobial defense of the intestine. Immunity. 2015;42:28-39.

30. Ward PP, Conneely OM. Lactoferrin: role in iron homeostasis and host defense against microbial infection. Biometals. 2004;17:203-8.

31. Brandtzaeg P. Secretory IgA: Designed for Anti-Microbial Defense. Front. Immunol. $2013 ; 4: 222$.

32. Neutra MR, Pringault E, Kraehenbuhl JP. Antigen sampling across epithelial barriers and induction of mucosal immune responses. Annu. Rev. Immunol. 1996;14:275-300.

33. Jang MH, Kweon MN, Iwatani K, et al. Intestinal villous M cells: an antigen entry site in the mucosal epithelium. Proc. Natl. Acad. Sci. U S A. 2004;101:6110-5.

34. Iwata M, Hirakiyama A, Eshima Y, Kagechika H, Kato C, Song SY. Retinoic acid imprints gut-homing specificity on T cells. Immunity. 2004;21:527-38.

35. Mora JR, Iwata M, Eksteen B, et al. Generation of gut-homing IgA-secreting B cells by intestinal dendritic cells. Science. 2006;314:1157-60.

36. Kiyono H, Fukuyama S. NALT- versus Peyer's-patch-mediated mucosal immunity. Nat. Rev. Immunol. 2004;4:699-710.

37. Berlin C, Berg EL, Briskin MJ, et al. Alpha 4 beta 7 integrin mediates lymphocyte binding to the mucosal vascular addressin MAdCAM-1. Cell. 1993;74:185-95.

38. Agace WW. T-cell recruitment to the intestinal mucosa. Trends. Immunol. 2008;29:514-22. 
39. Fukuyama Y, Tokuhara D, Sekine S, et al. Potential roles of CCR5(+) CCR6(+) dendritic cells induced by nasal ovalbumin plus Flt3 ligand expressing adenovirus for mucosal IgA responses. PLoS. One. 2013;8:e60453.

40. Fukuyama Y, Tokuhara D, Sekine S, et al. Notch-ligand expression by NALT dendritic cells regulates mucosal Th1- and Th2-type responses. Biochem. Biophys. Res. Commun. 2012;418:6-11.

41. Qadri F, Ali M, Chowdhury F, et al. Feasibility and effectiveness of oral cholera vaccine in an urban endemic setting in Bangladesh: a cluster randomised open-label trial. Lancet. 2015;386:1362-71.

42. Lebens M, Johansson S, Osek J, Lindblad M, Holmgren J. Large-scale production of Vibrio cholerae toxin B subunit for use in oral vaccines. Biotechnology (N Y). 1993;11:1574-8.

43. Sun DX, Mekalanos JJ, Taylor RK. Antibodies directed against the toxin-coregulated pilus isolated from Vibrio cholerae provide protection in the infant mouse experimental cholera model. J. Infect. Dis. 1990;161:1231-6.

44. Lee CK, Weltzin R, Thomas WD Jr, et al. Oral immunization with recombinant Helicobacter pylori urease induces secretory IgA antibodies and protects mice from challenge with Helicobacter felis. J. Infect. Dis. 1995;172:161-72. 
45. Hoshino Y, Saif LJ, Sereno MM, Chanock RM, Kapikian AZ. Infection immunity of piglets to either VP3 or VP7 outer capsid protein confers resistance to challenge with a virulent rotavirus bearing the corresponding antigen. J. Virol. 1988;62:744-8.

46. Mackow ER, Vo PT, Broome R, Bass D, Greenberg HB. Immunization with baculovirus-expressed VP4 protein passively protects against simian and murine rotavirus challenge. J. Virol. 1990;64:1698-703.

47. Nochi T, Yuki Y, Matsumura A, et al. A novel M cell-specific carbohydrate-targeted mucosal vaccine effectively induces antigen-specific immune responses. J. Exp. Med. 2007;204:2789-96.

48. Eldridge JH, Staas JK, Meulbroek JA, McGhee JR, Tice TR, Gilley RM. Biodegradable microspheres as a vaccine delivery system. Mol. Immunol. 1991;28:287-94.

49. Marinaro M, Staats HF, Hiroi T, et al. Mucosal adjuvant effect of cholera toxin in mice results from induction of T helper 2 (Th2) cells and IL-4. J. Immunol. 1995;155:4621-9.

50. Steinhagen F, Kinjo T, Bode C, Klinman DM. TLR-based immune adjuvants. Vaccine. 2011;29:3341-55.

51. Arakawa T, Chong DK, Langridge WH. Efficacy of a food plant-based oral cholera toxin B subunit vaccine. Nat. Biotechnol. 1998;16:292-7.

52. Yu J, Langridge WH. A plant-based multicomponent vaccine protects mice from enteric diseases. Nat. Biotechnol. 2001;19:548-52. 
53. Daniell H, Lee SB, Panchal T, Wiebe PO. Expression of the native cholera toxin B subunit gene and assembly as functional oligomers in transgenic tobacco chloroplasts. $J$. Mol. Biol. 2001;311:1001-9.

54. Lamphear BJ, Streatfield SJ, Jilka JM, et al. Delivery of subunit vaccines in maize seed. J. Control. Release. 2002;85:169-80.

55. Nochi T, Takagi H, Yuki Y, et al. Rice-based mucosal vaccine as a global strategy for cold-chain- and needle-free vaccination. Proc. Natl. Acad. Sci. U S A. 2007;104:10986-91.

56. Kapusta J, Modelska A, Figlerowicz M, et al. A plant-derived edible vaccine against hepatitis B virus. FASEB. J. 1999;13:1796-9.

57. Zhang H, Liu M, Li Y, et al. Oral immunogenicity and protective efficacy in mice of a carrot-derived vaccine candidate expressing UreB subunit against Helicobacter pylori. Protein. Expr. Purif. 2010;69:127-31.

58. Spangler BD. Structure and function of cholera toxin and the related Eschrichia coli heat-labile enterotocin. Microbiol. Rev. 1992;56:622-47.

59. Floss D, Falkenburg D, and Conrad U. Production of vaccines and therapeutic antibodies for veterinary applications in transgenic plants: an overview. Transgenic. Res. 2007;16: 315-32. 
60. Tacket C, Pasetti M, Edelman R, Howard J and Streatfield S. Immunogenicity of recombinant LT-B delivered orally to humans in transgenic corn. Vaccine. 2004;22: 4385-9.

61. Tacket C, Mason H, Losonsky G, Estes M, Levine M and Arntzen C. Human immune responses to a novel norwalk virus vaccine delivered in transgenic potatoes. $J$. Infect. Dis. 2000;182:302-5.

62. Tacket C. Plant-based vaccines against diarrheal diseases. Trans. Am. Clin. Climatol. Assoc. 2007;118:79-87.

63. Yusibov V, Stephen J, Streatfield S and Kushnir N. Clinical development of plant-produced recombinant pharmaceuticals: vaccines, antibodies and beyond. Human. Vaccin. 2011;7:313-21.

64. Kashima K, Yuki Y, Mejima M, et al. Good manufacturing practices production of a purification-free oral cholera vaccine expressed in transgenic rice plants. Plant. Cell. Rep. 2016;35:667-79.

65. Kashima K, Mejima M, Kurokawa S, Kuroda M, Kiyono H, Yuki Y. Comparative whole-genome analyses of selection marker-free rice-based cholera toxin B-subunit vaccine lines and wild-type lines. BMC. Genomics. 2015;16:48.

66. Kurokawa S, Kuroda M, Mejima M, et al. RNAi-mediated suppression of endogenous storage proteins leads to a change in localization of overexpressed cholera toxin B-subunit and the allergen protein RAG2 in rice seeds. Plant. Cell. Rep. 2014;33:75-87. 
67. Ogawa T, Kashima K, Yuki Y, et al. Seed metabolome analysis of a transgenic rice line expressing cholera toxin B subunit. Sci. Rep. 2017;7:5196.

68. Glass RI, Svennerholm AM, Stoll BJ, et al. Protection against cholera in breast-fed children by antibodies in breast milk. N. Engl. J. Med. 1983;308:1389-92.

69. Ruiz-Palacios GM, Calva JJ, Pickering LK, et al. Protection of breast-fed infants against Campylobacter diarrhea by antibodies in human milk. J. Pediatr. 1990;116:707-13.

70. Teh YH, Kavanagh TA. High-level expression of Camelid nanobodies in Nicotiana benthamiana. Transgenic. Res. 2010;19:575-86.

71. Virdi V, Coddens A, De Buck S, et al. Orally fed seeds producing designer IgAs protect weaned piglets against enterotoxigenic Escherichia coli infection. Proc. Natl. Acad. Sci. U S A. 2013;110:11809-14.

72. Ismaili A, Jalali-Javaran M, Rasaee MJ, Rahbarizadeh F, Forouzandeh-Moghadam M, Memari HR. Production and characterization of anti-(mucin MUC1) single-domain antibody in tobacco (Nicotiana tabacum cultivar Xanthi). Biotechnol. Appl. Biochem. 2007;47:11-9.

73. Giritch A, Marillonnet S, Engler C, et al. Rapid high-yield expression of full-size IgG antibodies in plants coinfected with noncompeting viral vectors. Proc. Natl. Acad. Sci. USA. 2006;103:14701-6. 
74. Peeters K, De Wilde C, Depicker A. Highly efficient targeting and accumulation of a $\mathrm{F}(\mathrm{ab})$ fragment within the secretory pathway and apoplast of Arabidopsis thaliana. Eur. J. Biochem. 2001;268:4251-60.

75. Fiedler U, Conrad U. High-level production and long-term storage of engineered antibodies in transgenic tobacco seeds. Biotechnol. 1995;13:1090-3.

76. Aladin F, Einerhand AWC, Bouma J, et al. In vitro neutralization of rotavirus infection by two broadly specific recombinant monovalent llama-derived antibody fragments. PLoS. One. 2012;7: e32949.

77. Yuki Y, Kurokawa S, Kozuka-Hata H, et al. Differential analyses of major allergen proteins in wild-type rice and rice producing a fragment of anti-rotavirus antibody. Regul. Toxicol. Pharmacol. 2016;76:128-136.

78. El-Kamary SS, Pasetti MF, Mendelman PM, et al. Adjuvanted intranasal Norwalk virus-like particle vaccine elicits antibodies and antibody-secreting cells that express homing receptors for mucosal and peripheral lymphoid tissues. J. Infect. Dis. 2010;202:1649-58.

79. Bernstein DI, Atmar RL, Lyon GM, et al. Norovirus vaccine against experimental human GII.4 virus illness: a challenge study in healthy adults. J. Infect. Dis. 2015;211:870-8.

80. Atmar RL, Bernstein DI, Harro CD, et al. Norovirus vaccine against experimental human Norwalk Virus illness. N. Engl. J. Med. 2011;365:2178-87. 
81. Sundararajan A, Sangster MY, Frey S, et al. Robust mucosal-homing antibody-secreting B cell responses induced by intramuscular administration of adjuvanted bivalent human norovirus-like particle vaccine. Vaccine. 2015;33:568-76.

82. Mason HS, Ball JM, Shi JJ, Jiang X, Estes MK, Arntzen CJ. Expression of Norwalk virus capsid protein in transgenic tobacco and potato and its oral immunogenicity in mice. Proc. Natl. Acad. Sci. USA. 1996;93:5335-40.

83. Velasquez LS, Shira S, Berta AN, et al. Intranasal delivery of Norwalk virus-like particles formulated in an in situ gelling, dry powder vaccine. Vaccine. 2011;29:5221-31.

84. Nicollier-Jamot B, Ogier A, Piroth L, Pothier P, Kohli E. Recombinant virus-like particles of a norovirus (genogroup II strain) administered intranasally and orally with mucosal adjuvants LT and LT(R192G) in BALB/c mice induce specific humoral and cellular Th1/Th2-like immune responses. Vaccine. 2004;22:1079-86.

85. Ettayebi K, Crawford SE, Murakami K, et al. Replication of human norovirus in stem cell-derived human enteroids. Science. 2016;353:1387-93.

86. Ettayebi K, Hardy ME. Recombinant norovirus-specific scFv inhibit virus-like particle binding to cellular ligands. Virol. J. 2008;5:21.

87. Lawn JE, Cousens S, Zupan J. Lancet Neonatal Survival Steering Team. 4 million neonatal deaths: when? Where? Why? Lancet. 2005;365:891-900. 
88. Stoll BJ, Hansen NI, Sánchez PJ, et al. National Institute of Child Health and Human Development Neonatal Research Network. Early onset neonatal sepsis: the burden of group B Streptococcal and E. coli disease continues. Pediatrics. 2011;127:817-26.

89. Nair H, Nokes DJ, Gessner BD, et al. Global burden of acute lower respiratory infections due to respiratory syncytial virus in young children: a systematic review and meta-analysis. Lancet. 2010;375:1545-5.

90. Mendelman PM, Cordova J, Cho I. Safety, efficacy and effectiveness of the influenza virus vaccine, trivalent, types $\mathrm{A}$ and $\mathrm{B}$, live, cold-adapted (CAIV-T) in healthy children and healthy adults. Vaccine. 2001;19:2221-6.

91. Centers for Disease Control and Prevention. Recommended Immunizations for Children from Birth Through 6 Years Old. Available at : http://www.cdc.gov/vaccines/parents/downloads/parent-ver-sch-0-6yrs.pdf Accessed Apr 20, 2014.

92. Centers for Disease Control and Prevention. Recommended Immunizations for Adults by Age. Available at : http://www.cdc.gov/vaccines/schedules/downloads/adult/adult-schedule-easy-read.pdf Accessed Apr 20, 2014.

93. Nguyen M, Leuridan E, Zhang T, et al. Acquisition of adult-like TLR4 and TLR9 responses during the first year of life. PLoS. One. 2010;5:e10407. 
94. Kollmann TR, Crabtree J, Rein-Weston A, et al. Neonatal innate TLR-mediated responses are distinct from those of adults. J. Immunol. 2009;183:7150-60.

95. Schüller SS, Sadeghi K, Wisgrill L, et al. Preterm neonates display altered plasmacytoid dendritic cell function and morphology. J. Leukoc. Biol. 2013;93:781-8.

96. Levy O, Zarember KA, Roy RM, Cywes C, Godowski PJ, Wessels MR. Selective impairment of TLR-mediated innate immunity in human newborns: neonatal blood plasma reduces monocyte TNF-alpha induction by bacterial lipopeptides, lipopolysaccharide, and imiquimod, but preserves the response to R-848. J. Immunol. 2004; 173:4627-34.

97. Nohmi K, Tokuhara D, Tachibana D, et al. Zymosan induces immune responses comparable with those of adults in monocytes, dendritic cells, and monocyte-derived dendritic cells from cord blood. J. Pediatr. 2015;167:155-62.

98. Yanai S, Tokuhara D, Tachibana D, et al. Diabetic pregnancy activates the innate immune response through TLR5 or TLR1/2 on neonatal monocyte. J. Reprod. Immunol. 2016;117:17-23. 


\section{Figure legends}

Figure 1. The gut mucosal immune system.

a. Pathogen-specific and -nonspecific defense in the small intestine.

The epithelial cell and mucus layers physically protect against pathogen invasion. Antimicrobial proteins (e.g., defensins, lactoferrin) chemically kill or inactivate pathogens or inhibit bacterial growth. Pathogen-specific defense is provided by secretory $\operatorname{IgA}$ and cytotoxic T lymphocytes (CTLs). Gut-associated lymphoid tissue (GALT), typically Peyer's patches (PPs), is crucial in the induction of pathogen-specific immune responses. PPs consist of the B-cell-dense follicular zone, including germinal centers, where class-switching of B cells to produce IgA occurs predominantly, and the interfollicular regions, which are rich in T cells and dendritic cells (DCs). PPs are surrounded by the follicle-associated epithelium (FAE), which contains cells that lack the brush border characteristic of epithelial cells and which are specialized for antigen uptake (i.e., $\mathrm{M}$ cells). Beneath the $\mathrm{M}$ cells, antigen-presenting cells (APCs) such as DCs, B cells, and T cells construct the immune networks that lead to the induction of acquired immunity and oral tolerance.

b. Common mucosal immune system for the induction of antibody-specific IgA.

M cells within the epithelial layer transport antigens from the lumen to APCs, such as DCs, which process and present antigens to CD4+ T cells. Stimulated T cells preferentially induce IgA-committed B-cell development in the germinal center. After class-switching to IgA 
production and affinity maturation, B cells rapidly migrate from PPs to the regional mesenteric lymph nodes. Antigen-specific $\mathrm{CD} 4^{+} \mathrm{T}$ cells and $\operatorname{IgA}^{+} \mathrm{B}$ cells migrate through the thoracic duct and blood circulation to reach the intestinal lamina propria, an effector site. $\operatorname{IgA}^{+} \mathrm{B}$ cells and plasmablasts then differentiate into IgA-producing plasma cells in the presence of cytokines, such as IL- 5 and IL-6, which are produced by Thelper 2 (Th2) cells. c. Intracellular transport mechanism of sIgA. Dimeric or polymeric IgA secreted from plasma cells in the lamina propria binds to polymeric immunoglobulin receptors (pIgRs) at the basolateral surface of epithelial cells and is transported to the lumen, where cleavage of the pIgR-dimeric IgA complex releases sIgA into the lumen. sIgA can neutralize the biological effects of an antigen, inhibit pathogen, and prevent toxin attachment or entry. sIgA-antigen complexes can be 'reverse-transcytosed' by M cells for presentation and processing by APCs, leading to an adaptive immune response against the antigen. Another role of $\operatorname{sg} \mathrm{A}$ is intracellular neutralization: endosomes carrying SIgA from the basolateral surface react with endocytosed virus or toxins, after which pathogen-specific sIgA neutralizes viral proteins or bacterial toxins. 


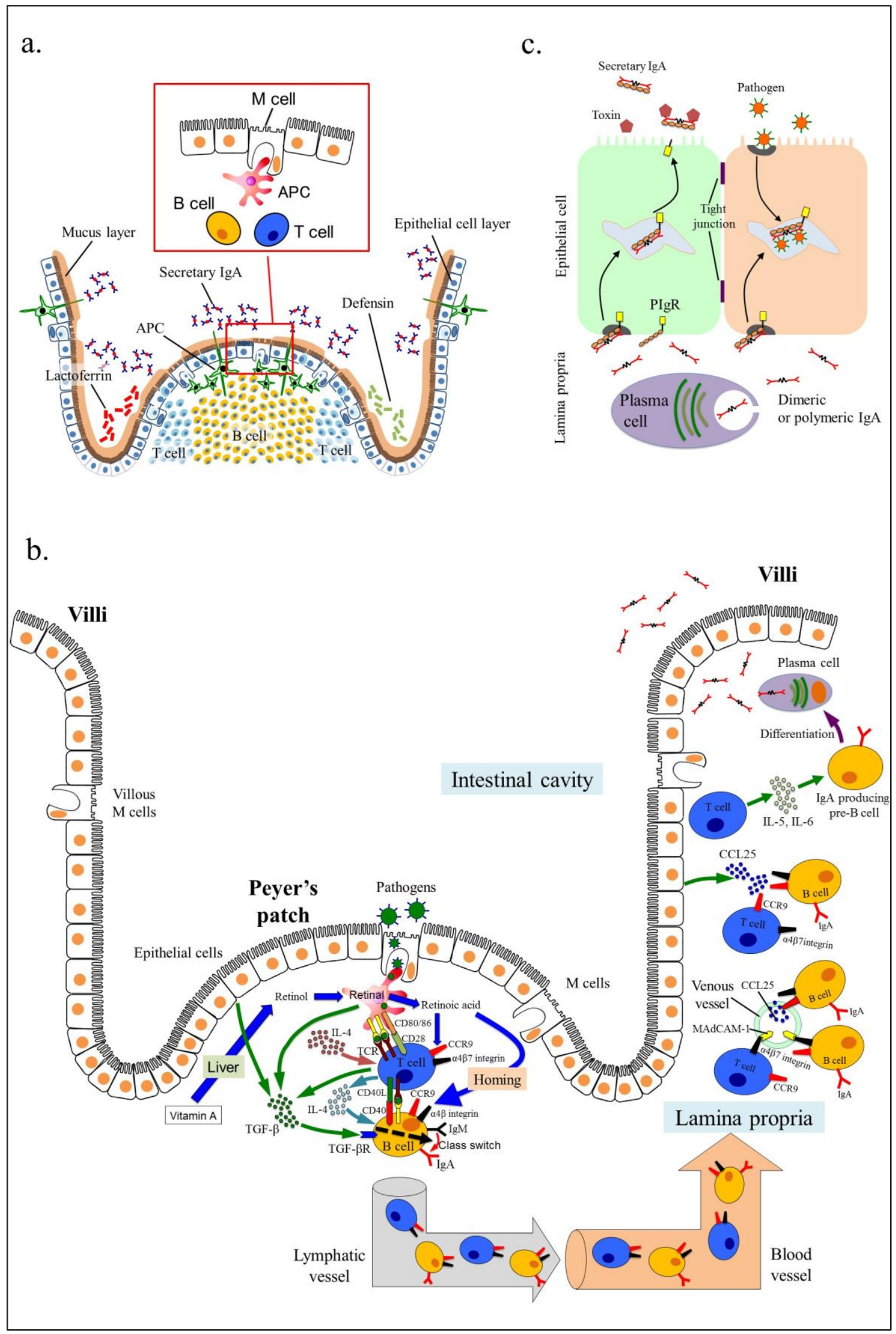


Figure 2. Schema of rice-based oral cholera vaccine production.

The CTB gene of $V$. cholerae was inserted into a T-DNA plasmid with endosperm specific promotor. The resulting T-DNA plasmid was transformed in the rice callus, a mass of undifferentiated rice plant cells, using an Agrobacterium-mediated method. Seeds of rice plants, which were regenerated from the transformed rice calluses, expressed CTB $(30 \mu \mathrm{g} / \mathrm{seed})$. Oral immunization of mice with rice-based CTB elicited CTB-specific serum IgG and intestinal SIgA antibodies and protected the animals from CT-induced diarrhea via mucosal CTB-specific SIgA-mediated inhibition of CT binding to epithelial cells. In addition, oral immunization with rice-based CTB that had been stored at room temperature for $>3$ years induced CTB-specific serum IgG and intestinal SIgA responses at the same levels as those induced by freshly harvested rice-based CTB in mice.

CT: cholera toxin, CTA: cholera toxin A subunit, CTB: cholera toxin B subunit, T-DNA: transfer DNA 


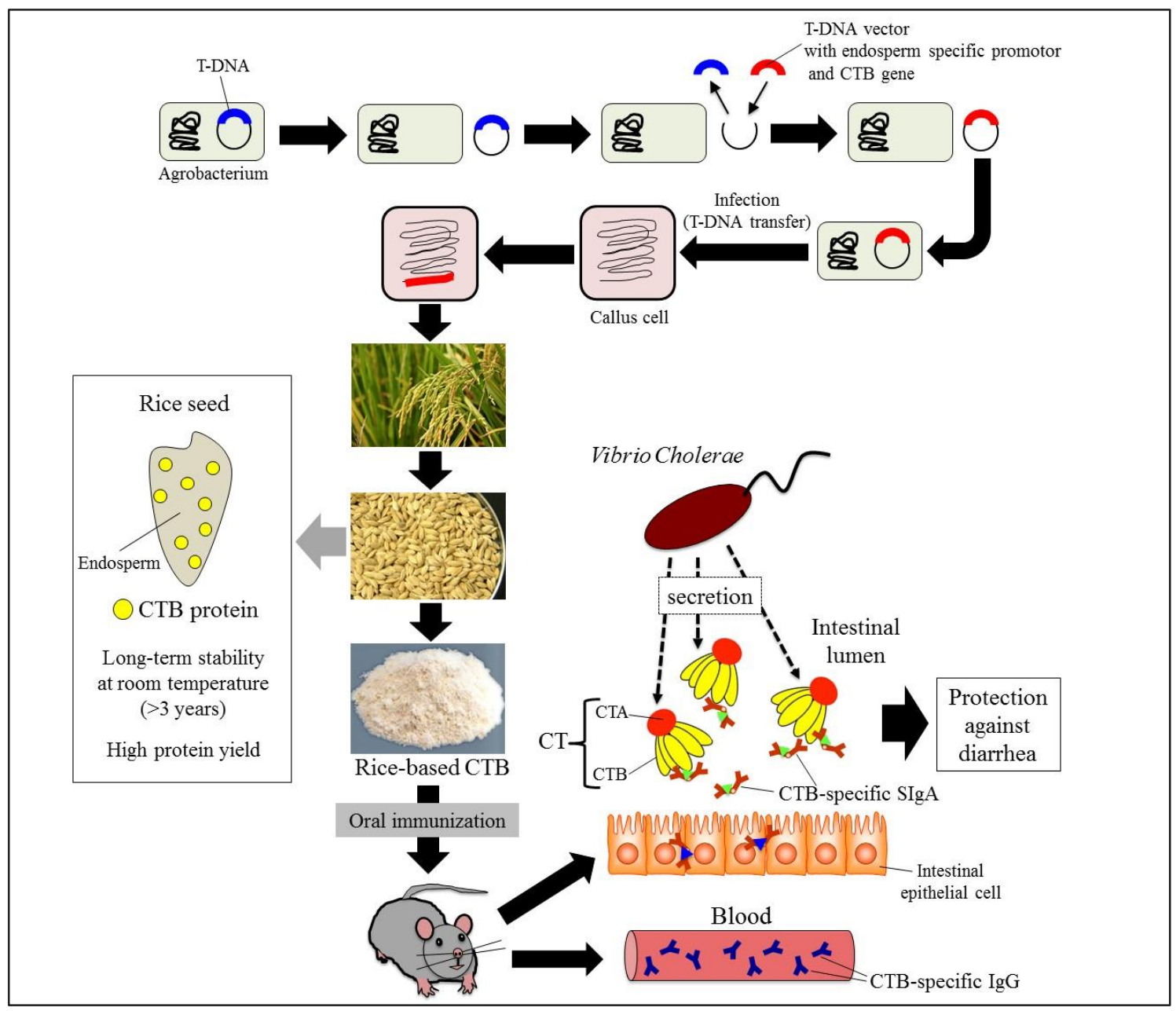


Figure 3. Schema of rice-based oral antibody production.

In addition to conventional antibodies (with heavy and light chains), camelids (e.g., camels, llamas) also produce antibodies with solely the heavy chain. The variable domain (VHH) of the heavy-chain antibodies has binding properties. An anti-rotavirus protein 1(ARP1), that is a rotavirus-specific VHH, was selected from a library of VHH fragments generated from llamas immunized with rhesus rotavirus (G3). The gene encoding ARP1 was synthesized with an optimized codon usage for plants and inserted into a binary T-DNA vector. This vector contains a cassette for overexpression of ARP1 and a combination cassette for RNAi suppression of production of the major rice endogenous storage proteins, prolamin and glutelin. The plasmid was transformed into a rice plants, using a Agrobacterium-mediated method. The expression of the prolamin and glutelin was suppressed and the ARP1 protein was predominantly expressed in the transgenic rice. The ARP1 solution extracted from the rice-based ARP1 effectively reduced rotavirus-induced diarrhea in neonatal pups. Rice-based ARP1 retained in vitro neutralizing activity after long-term storage (>1 yr) and boiling and conferred protection in mice even after heat treatment at $94^{\circ} \mathrm{C}$ for 30 minutes.

VH: variable domain of the heavy chain, VL: variable domain of the light chain, VHH: variable domain of heavy chain of heavy-chain antibody, $\mathrm{CH}$ : constant domain of the heavy chain. CL: constant domain of the light chain 


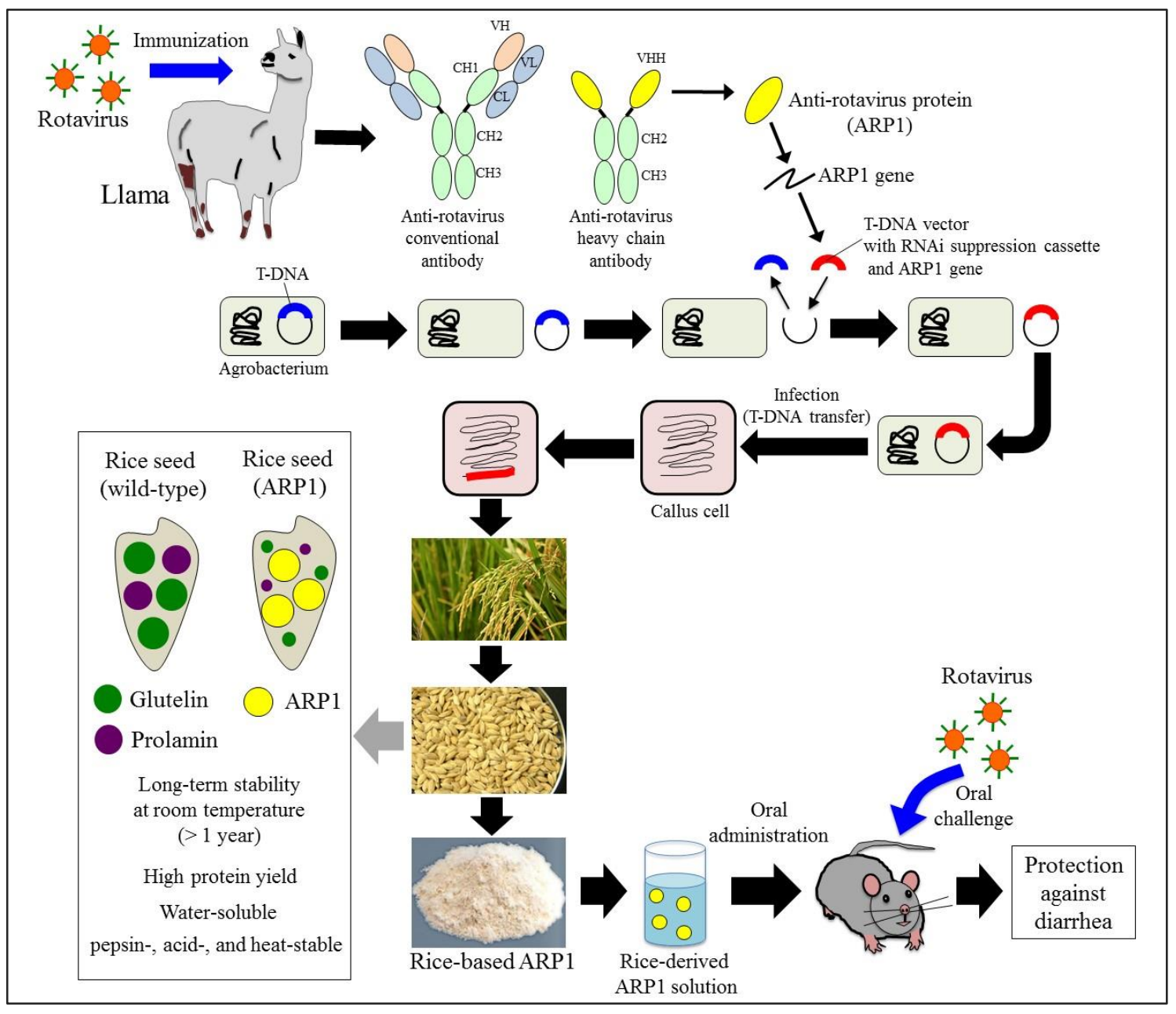

